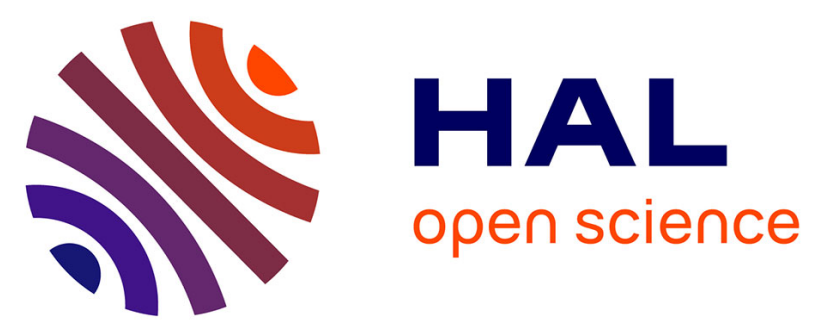

\title{
Bioactive glass coating on gelatin scaffolds at ambient temperature: easy route to make polymer scaffolds become bioactive
}

Jonathan Lao, Xavier Dieudonné, Mhammed Benbakkar, Edouard Jallot

\section{To cite this version:}

Jonathan Lao, Xavier Dieudonné, Mhammed Benbakkar, Edouard Jallot. Bioactive glass coating on gelatin scaffolds at ambient temperature: easy route to make polymer scaffolds become bioactive. Journal of Materials Science, 2017, 52 (15), pp.9129-9139. 10.1007/s10853-017-0781-7 . hal-01636802

\section{HAL Id: hal-01636802 \\ https://hal.uca.fr/hal-01636802}

Submitted on 4 Mar 2021

HAL is a multi-disciplinary open access archive for the deposit and dissemination of scientific research documents, whether they are published or not. The documents may come from teaching and research institutions in France or abroad, or from public or private research centers.
L'archive ouverte pluridisciplinaire HAL, est destinée au dépôt et à la diffusion de documents scientifiques de niveau recherche, publiés ou non, émanant des établissements d'enseignement et de recherche français ou étrangers, des laboratoires publics ou privés. 


\title{
Bioactive glass coating on gelatin scaffolds at ambient temperature: easy route to make polymer scaffolds become bioactive
}

\author{
Jonathan Lao ${ }^{1, *}$ (D), Xavier Dieudonné ${ }^{1}$, Mhammed Benbakkar ${ }^{2}$, and Édouard Jallot ${ }^{1}$ \\ ${ }^{1}$ CNRS/IN2P3, Laboratoire de Physique Corpusculaire, Clermont Université, Université Clermont Auvergne, BP 80026, \\ 63171 Aubière Cedex, France \\ ${ }^{2}$ Laboratoire Magmas et Volcans, CNRS-OPGC-IRD, Université Clermont Auvergne, Clermont-Ferrand, France
}

Increasing the bioactivity of polymeric materials used for bone repair is a con-cern that can be achieved by loading growth factors or using in vitro tissue engineering approach. However, these techniques may have to address regu-latory issues as the implants are shifted from the medical device class to the more constraining drug delivery systems. Alternatively, implants can be coated with bioceramics to achieve bioactivity, but existing coating processes can hardly be applied to polymers because they usually involve thermal treatments or sintering. Here we report an efficient way of coating a bioactive glass phase onto a complex polymeric substrate, namely gelatin scaffolds with controlled spherical porosity, at ambient temperature through a dip-coating process. A multiscale analysis of the bioactive glass-coated gelatin scaffolds properties has been carried out. Homogeneous and remarkably uniform layer of $\mathrm{SiO}_{2}-\mathrm{CaO}$ bioactive glass is obtained. The bioactive glass coating exhibits a very high and fast apatite-forming ability, with full mineralization of the coating being achieved in less than $24 \mathrm{~h}$ contact with body fluids. Importantly, the mineral-ization takes place homogeneously throughout the scaffold while the remark-able uniformity and thickness regularity of the coating are preserved. These features should enhance the in vivo behaviour of polymer scaffolds and make reconsider the interest of non-bioactive polymers for tissue engineering.

\section{Introduction}

Accelerating bone healing at early implantation time is one of the main concerns when developing new biomaterials. [1]. As an implant first interacts through surface reactions, adequate modifications of its surface can enhance or introduce new implant properties regarding, e.g. bioactivity, osteoconduction, biocompatibility and mechanical response [2]. A large number of techniques have been developed to

Address correspondence to E-mail: lao@clermont.in2p3.fr 
improve the surface compatibility of medical devices. Among them, surface coating with bioceramics is an efficient way of conferring bioactivity to the implant, i.e. the ability to bond with host tissues. For example, a biocompatible calcium phosphate coating can be applied to the stem of hip endoprostheses or to dental root implants, in order to support osseointegration $[3,4]$. Due to its similarity with the inorganic content of bone, this coating will be an adequate site for the adhesion and further proliferation of bone cells and will finally result in a strong and lasting bond between the implant and surrounding host tissues [3-5]. Since bioactive glasses (BG) are known to demonstrate the highest bioactivity among synthetic materials [6], it can be of great benefit to take advantage of their superior properties to coat implants. Metallic prostheses have been coated with BG with the aim of improving the implants stability by bonding them to host tissues [7-9] and preventing fibrous encapsulation usually induced by metal implants. For instance titanium implants were dipcoated with a $\mathrm{SiO}_{2}-\mathrm{CaO}-\mathrm{Na}_{2} \mathrm{O}-\mathrm{P}_{2} \mathrm{O}_{5}-\mathrm{K}_{2} \mathrm{O}-\mathrm{MgO}-\mathrm{B}_{2} \mathrm{O}$ glass before implantation in rabbit femurs and showed superior bone formation in vivo compared to non-coated implants [10]. A clinical trial demonstrated that glass-coated titanium implants behaved as well as hydroxyapatite-coated implants after 1-year implantation [11].

However, there is only a scarce literature about bioactive coating - and in particular BG coating-on polymer matrices. This is a challenging task since thermal treatments cannot be handled, to avoid the polymer thermal degradation. Kokubo, Tanahashi et al. [12-15] put a polymer substrate in direct contact with $\mathrm{SiO}_{2}-\mathrm{CaO}$ BG particles soaked in simulated body fluid (SBF). This allowed the formation of apatite nuclei at the polymer surface, that were further grown into a dense, uniform apatite layer by immersing the polymer again into another solution with ion concentrations 1.5 times those of SBF. In addition to being slow (about 1 week required to obtain a uniform coating), this 2-steps process can hardly be used to uniformly coat the inner walls of porous matrices or complex shapes like scaffolds, since the apatite nuclei are only formed on the material surface that is directly facing the BG particles. Miyaji et al. [16], followed by Oliveira et al. $[17,18]$, soaked polymer matrices into a sodium silicate gel in order to obtain a $\mathrm{SiO}_{2}-\mathrm{Na}_{2} \mathrm{O}$ glass coating. They demonstrated this coating to be an effective initiator of apatite nucleation on polymer substrates with complex shapes like scaffolds [17]. However, conducting the process remains heavy, since an incubation period of 7 days in SBF is first needed to induce the formation of apatite nuclei, followed by 7-14 days soaking in concentrated SBF solutions $(1.5 \times$ to $2 \times \mathrm{SBF}$ ionic concentration) for efficient growth of the apatite layer. Moreover, there is only little data about the in vivo behaviour and corrosion of sodium silicate [19]. There have been finally very few attempts to coat BG directly onto polymeric materials. Leach et al. [20], Day et al. [21] and Li et al. [22, 23] made slurries consisting of micron-sized BG particles to coat PLGA, PGA or PET, respectively. However, they reported either a non-uniform coating to be obtained, or a loss of porosity inside the material [21], or insufficient concentrations of BG particles in the coating unable to induce a robust osteogenic action [20]. Another drawback of this technique is that the BG particles are only deposited onto the polymeric substrate and are likely to be released once in contact with body fluids. Stamboulis et al. [24], Niiranen et al. [25] proposed a variant where the BG particles were "implanted" into a Vicryl polymer matrix by pressing the coating using a uniaxial press at 2-160 MPa. Of course, it is unconceivable to apply this method to polymer scaffolds since they would be flattened.

Here we propose a convenient way to coat polymer scaffolds with BG. BG usually need to be sintered, either as a result of their method of production, which derives from the fusion process or the sol-gel process, or for the coating to adhere [6]; but here our process is fully conducted at ambient temperature. Indeed using calcium alkoxide as a calcium precursor in the sol-gel route makes it possible to obtain silicate glasses with calcium ions well incorporated into the inorganic network without the need of thermal treatments otherwise necessary [26-29]. The polymer scaffolds here coated were based on gelatin, since gelatin is obtained from collagen and, therefore, naturally contains biologically relevant functional groups [30]. It shows good cell viability without any antigenicity and has long been used in pharmaceutics, wound dressing and adhesives [31-34]. Extensive in vivo data on the suitability of gelatin-based scaffolds for bone reconstruction are available [35-39]. In this study bovine gelatin scaffolds with controlled porosity were fabricated using the microsphere leaching technique [40, 41]; they were then 
dip-coated with a BG alkoxide sol. The physicochemical properties and potential towards bone mineral formation of these BG-coated gelatin scaffolds are investigated.

\section{Materials and methods}

\section{Gelatin scaffolds synthesis}

3-D interconnected macroporous gelatin structures are obtained using the microspheres-leaching technique [40, 42]. A $12.7 \mathrm{wt} \%$ gelatin (type $\mathrm{B}, 225 \mathrm{~g}$ bloom number, Aldrich) aqueous solution was first prepared in a thermostated bath at $37^{\circ} \mathrm{C}$. After full completion of gelatin dissolution, the gelatin sol was infiltrated into a compact stack of PMMA microspheres (100-300 $\mu \mathrm{m}$ diameter, Kisker Biotech) in cylindrical polyethylene moulds and centrifugated at $6000 \mathrm{rpm}$. Gelation and ageing of the blend was performed at room temperature for $24 \mathrm{~h}$. The obtained cylinders were immersed in acetone for $24 \mathrm{~h}$ to dissolve the PMMA porogen spheres. This operation was renewed two times. Macroporous gelatin scaffolds with controlled porosity were obtained and further dried in an oven at $40{ }^{\circ} \mathrm{C}$ for $24 \mathrm{~h}$. Finally, the gelatin scaffolds were crosslinked in a $1 \mathrm{wt} \%$ glutaraldehyde/ethanol solution for $24 \mathrm{~h}$. The reticulation of the gelatin was indeed required to prevent its dissolution in the BG sol during the dip-coating process, and to prevent premature degradation of the scaffolds after implantation or when interacting with body fluids. The crosslinked gelatin scaffolds were rinsed in ethanol and dried at room temperature.

\section{$\mathrm{SiO}_{2}-\mathrm{CaO}$ BG sol-gel synthesis and dip-coating of gelatin scaffolds}

Hydrolysis of tetraethylorthosilicate (TEOS, Aldrich, 99\% purity) was performed in ethanol (absolute $99.8 \%$, Aldrich) containing $2 \mathrm{M} \mathrm{HCl}$ (obtained from $37 \%$ fuming, Aldrich), following a volume ratio EtOH:HCl = 6:1 and molar ratio EtOH:TEOS = 6:1. In parallel, calcium ethoxide (ABCR) was dispersed in absolute ethanol. Then the two solutions were mixed in stoichiometric proportions, in order to obtain a $75-25 \mathrm{wt} \% \mathrm{SiO}_{2}-\mathrm{CaO}$ glass at a $12.7 \mathrm{wt} \%$ concentration in the sol. A translucent and yellowish sol was obtained and left for condensation for a few hours.
The cylindrical gelatin scaffolds were then simply dipped into the BG sol for $1 \mathrm{~min}$ and left for drying for $15 \mathrm{~min}$. These operations were repeated again 1 time.

\section{SEM observations}

The scaffolds were carbon-coated using a carbon thread prior to analysis. Observations were conducted on a Hirox SH-3000 mini-SEM operating at $10 \mathrm{kV}$ voltage.

\section{Porosity calculation}

Pore diameters and interconnections were extracted from SEM pictures thanks to the Image J software. This method of measurement is here preferable to traditional mercury intrusion porosimetry which is limited to the characterization of pores under $250 \mu \mathrm{m}$ [43]. Total porosity of the scaffolds was deduced from apparent density of cylindrical scaffolds of measured weights and dimensions and from gas pycnometry measurements $\left(1.5 \mathrm{~g} / \mathrm{cm}^{3}\right.$ scaffold skeletal density) using the formula: \%porosity $=\left(1-\mathrm{d}_{\text {apparent }} /\right.$ $\mathrm{d}_{\text {skeletal }}$ ).

\section{Apatite-forming ability test in SBF}

The ISO-23317 standard procedure was followed. Briefly, c- SBF2 [44], a protein-free solution of inorganic composition close to human blood plasma, was prepared following recommendations of Bohner et al. [45]. Scaffolds were immersed in SBF at a $1 \mathrm{mg} / \mathrm{mL}$ ratio for up to 7 days at a constant temperature of $37^{\circ} \mathrm{C}$. After interaction, aliquots of the solution are used for determination of the fluids composition by ICP-AES, while the scaffolds are carefully rinsed with pure ethanol and dried to avoid further mineralization reactions.

\section{TEM observations}

Prior to observation, the scaffolds were embedded in resin (AGAR, Essex, England). 100-nm ultrathin cross sections of materials were cut using a LEICA EM UC6 with diamond knives. A Phillips CM 20 microscope ( $\mathrm{LaB}_{6}$ thermoelectronic gun) operating at $200 \mathrm{kV}$ was used to study the microstructure and morphology of hybrid scaffolds before and after soaking in SBF. The images were recorded with a Keenview CCD camera 
Figure 1 a-b SEM

micrographs of bioactive glass-coated gelatin scaffold, c-d PIXE chemical maps showing the cross-sectional distribution of silicon and calcium inside the scaffold. e$f$ TEM magnification of previous images revealing the morphology of BG coated onto the gelatin struts. (a)

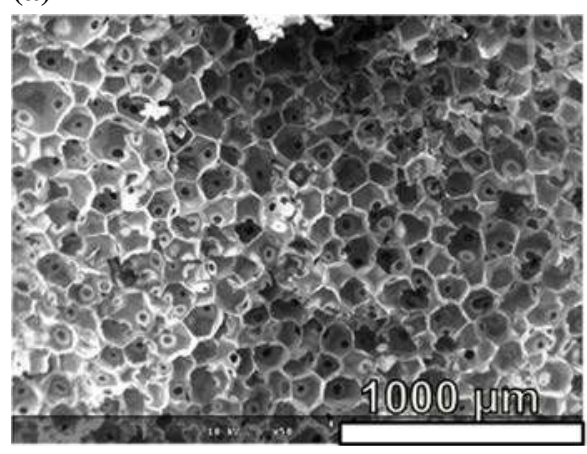

(c)

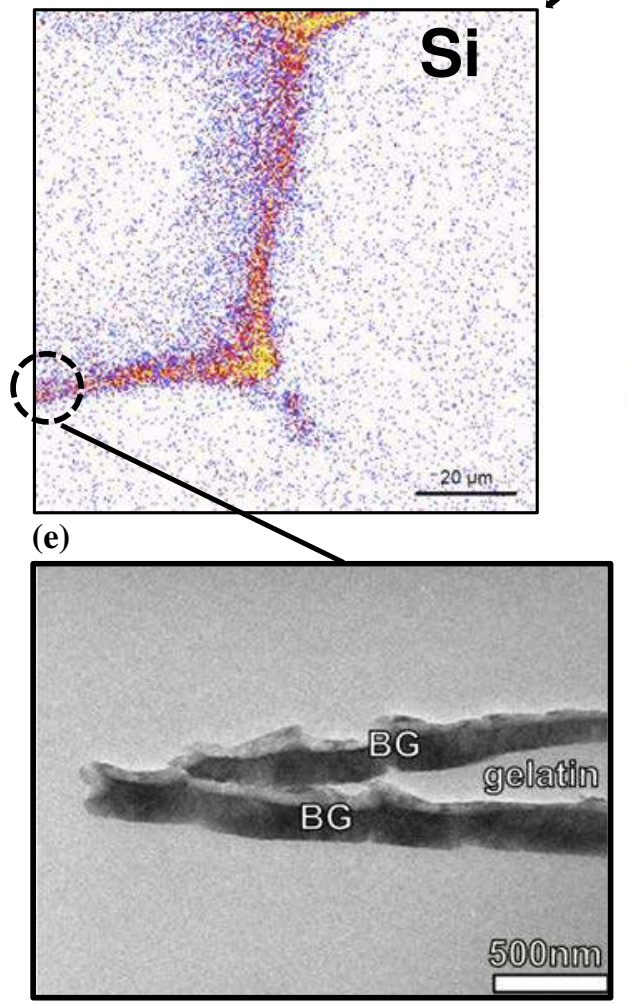

(b)
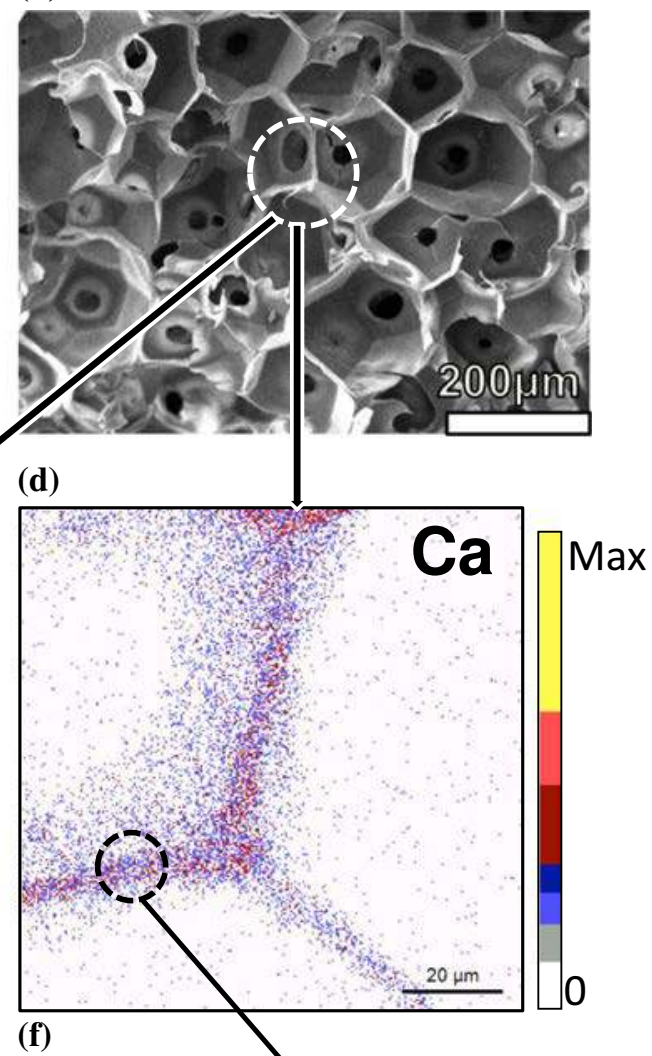

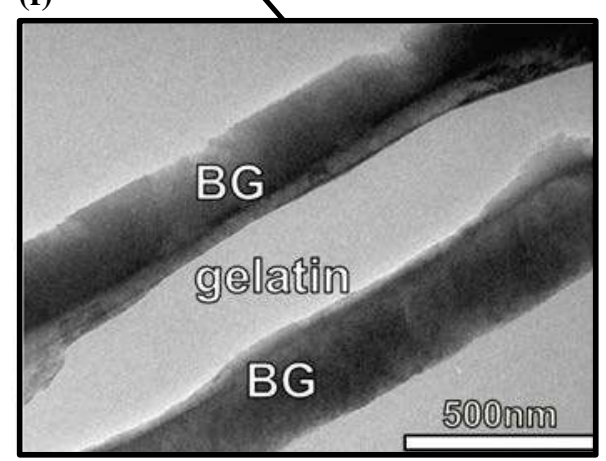

with $18.67 \mu \mathrm{m}$ pixel size and processed with the analysis software.

\section{FTIR analysis}

The FTIR was conducted on a Nicolet spectrometer 380. Prior to analysis the materials were grinded into a fine powder and then mixed with KBr (Aldrich, IR grade) at a $3 \mathrm{wt} \%$ concentration. They are finally pressed into pellets that are ready for FTIR analysis.

\section{PIXE ion beam analysis}

Particle-Induced X-ray Emission (PIXE) quantitative microanalysis is very similar to SEM-EDS or electron microprobe analysis, but provides a deeply increased sensitivity due to limited bremsstrahlung background radiation of incident heavy charged particles. It allows visualizing the chemical changes occurring inside BG-coated scaffolds during interaction with SBF. After interaction with SBF, the scaffolds are dried and embedded in resin (AGAR, Essex, England). Cross sections of materials (40 $\mu \mathrm{m}$ thick) were cut using a LEICA RM 2145 microtome. PIXE microanalysis of the cross sections was carried out at the AIFIRA platform (CENBG, France) using a 3-MeV incident proton beam (beam diameter of $1 \mu \mathrm{m}$ ). An $80 \mathrm{~mm}^{2} \mathrm{Si}(\mathrm{Li})$ detector (equipped with a $12-\mu \mathrm{m}$-thick beryllium window and an aluminium funny filter 


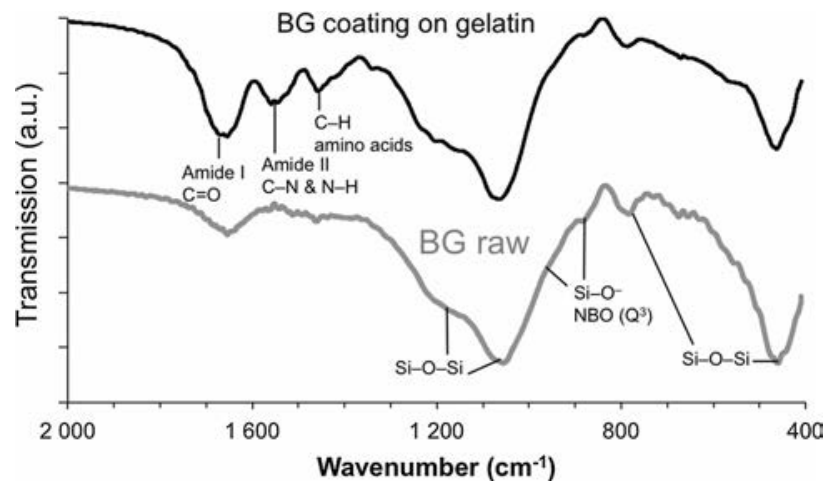

Figure 2 FTIR spectra of $\mathrm{SiO}_{2}-\mathrm{CaO}$ bioactive glass coated on the gelatin scaffold compared to raw $\mathrm{SiO}_{2}-\mathrm{CaO} \mathrm{BG}$.

with a tiny hole of $2 \mathrm{~mm}$ ) orientated at $135^{\circ}$ with respect to the incident beam axis was used for X-ray detection,. Quantification was done using the Gupixwin software after calibration against NIST 620 (soda-lime glass) standard reference material.

\section{ICP-AES}

Five 0 to $50 \mathrm{ppm}$ solutions containing the elements to analyse $(\mathrm{P}, \mathrm{Si}, \mathrm{Mg}, \mathrm{Ca})$ have been prepared for calibration. A ULTIMA-C spectrometer (Horiba scientific, Jobin-Yvon) was used. This instrument combines two spectrometers to measure emission lines from elements excited in a single plasma torch: one polychromator and one scanning monochromator. The polychromator was used for the simultaneous measurement of emission lines from $\mathrm{Si}, \mathrm{Ca}$ and $\mathrm{Mg}$. The scanning high-resolution monochromator was used for sequential determination of emission line from $\mathrm{P}$. The ICP-AES operating conditions were the following: incident power $1.1 \mathrm{~kW}$; reflected power $<15 \mathrm{~W}$; plasma gas flow rate $16 \mathrm{l} / \mathrm{min}$; permanent sheath gas flow rate $0.21 / \mathrm{min}$; carrier gas flow rate $0.8 \mathrm{l} / \mathrm{min}$; and solution uptake $0.9 \mathrm{l} / \mathrm{min}$. The analytical lines used were $213.618 \mathrm{~nm}(\mathrm{P}), 288.158$ (Si), $279.553(\mathrm{Mg})$ and $334.940(\mathrm{Ca})$.

\section{Compression tests}

Mechanical properties of the scaffolds were measured under compression on cylindrical samples (diameter $=$ height $=10 \mathrm{~mm}$ ) using a UTS testing machine, equipped with a $50 \mathrm{kN}-$ load cell and circular plates, at a crosshead speed of $0.5 \mathrm{~mm} / \mathrm{min}$.

\section{Results and discussion}

To elaborate a BG coating without thermal treatment, it is necessary to use a $100 \%$ alkoxide route, which implies using a calcium alkoxide as calcium precursor [29]. Any other calcium source, such as calcium salts, involve thermal stabilization at high temperature $\left(>400{ }^{\circ} \mathrm{C}\right)$ required to make calcium enter the silicate network [26, 46]. On the contrary, calcium alkoxides can readily be incorporated into the silicate network at room temperature, as a result of the hydrolysis/condensation reactions. Yet the known instability of calcium alkoxides has restricted their use due to the difficult processability of obtained sols [47]. To limit this instability, we previously reported that limiting the amount of water in the sol was the key as calcium alkoxides are very sensitive to water hydrolysis [48]. In our synthesis, tetraethylorthosilicate (TEOS) is first hydrolysed in a slightly acidified alcoholic solution and then calcium ethoxide $\mathrm{Ca}(\mathrm{OEt})_{2}$ is added.

Figure 1 shows the multiscale characterization of as obtained BG-coated gelatin scaffolds, from the macroscopic down to the submicron scale. On SEM micrographs (Fig. 1a, b) it can be seen that the scaffolds own a well-ordered porosity with highly interconnected pores. The diameters of pores lie in the $100-200 \mu \mathrm{m}$ range, with interconnections 20-50 $\mu \mathrm{m}$. The scaffold walls are very thin, with struts less than a few microns thick. Figure 1c, d displays the chemical distribution of silicon and calcium inside a pore strut. Si and $\mathrm{Ca}$ are homogeneously distributed, demonstrating both the uniformity of the BG coating over the gelatin substrate and the intrinsic homogeneity of the $\mathrm{SiO}_{2}-\mathrm{CaO}$ glass. Figure 1e, $\mathrm{f}$ is magnification of the struts as observed in TEM. Here enough contrast is provided to allow distinguishing between the organic gelatin substrate and the $\mathrm{SiO}_{2}-\mathrm{CaO}$ BG coating. The dark regions correspond to areas of higher density or higher average atomic number, leading to high absorption of the electron beam, such as the inorganic $\mathrm{SiO}_{2}-\mathrm{CaO}$ BG coating. On the contrary, gelatin domains appear as bright areas since the organic matrix is associated to both lower density and $\mathrm{Z}$ atomic number. TEM observation of ultrathin cross sections of BG-coated gelatin scaffolds reveals our dip-coating process is successful to yield a uniform glass layer around $200 \mathrm{~nm}$ thickness that surrounds the gelatin struts of the scaffold. The BG layer is 
Figure 3 Images of BGcoated gelatin scaffolds after 7 days soaking in simulated body fluid, $\mathbf{a}-\mathbf{b}$ SEM, and $\mathbf{c}-$ d TEM observations highlighting the formation of a uniform bone-like hydroxyapatite (HA) layer. (a)

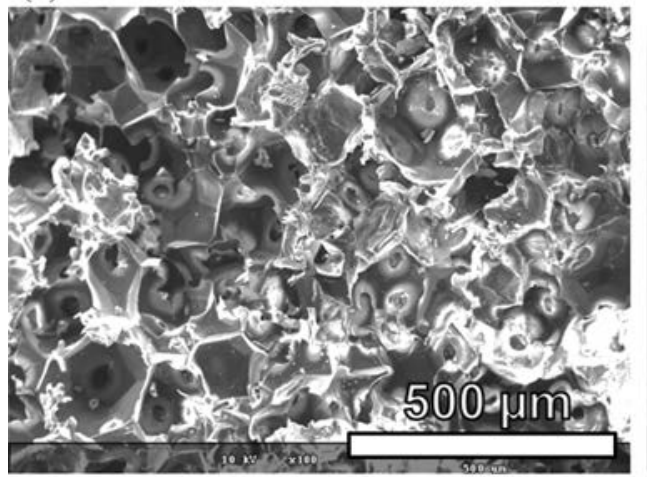

(c)

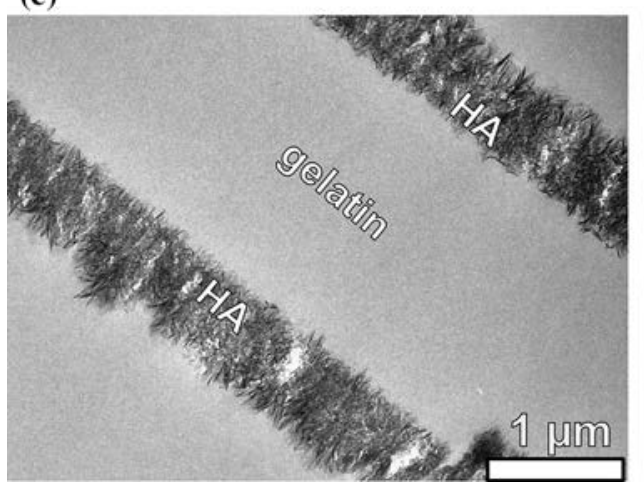

(b)

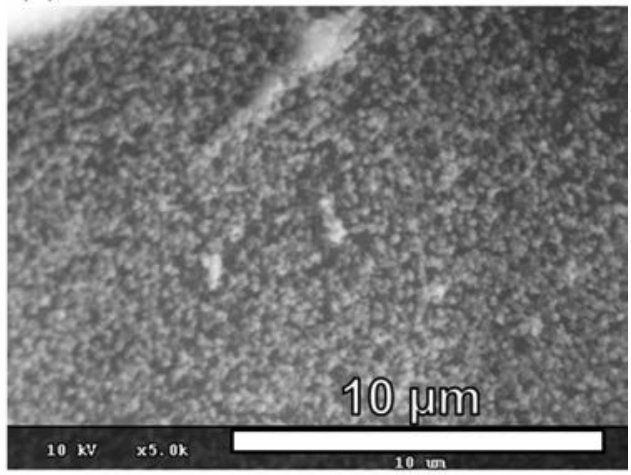

(d)

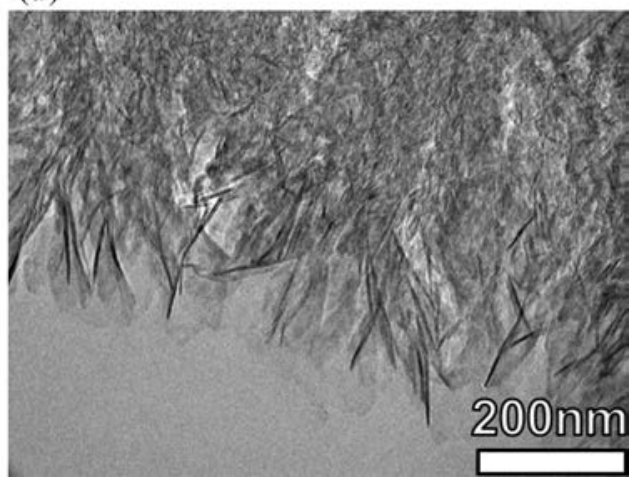

dense, as expected from the acid-catalysed sol-gel route we employed, which leads to polymeric and dense silicate gels [49].

The atomic structure of $\mathrm{SiO}_{2}-\mathrm{CaO}$ BG coatings was investigated through FTIR spectroscopy and compared to raw $\mathrm{SiO}_{2}-\mathrm{CaO}$ glass derived from the same synthesis but not coated onto gelatin scaffolds. Figure 2 evidences the characteristic absorption bands attributed to the transverse optical (TO) modes of siloxane Si-O-Si bridges: at $\sim 450 \mathrm{~cm}^{-1}$ a low frequency mode is assigned to the TO rocking motions of the oxygen bridging two adjacent $\mathrm{Si}$ atoms [50]; near $800 \mathrm{~cm}^{-1}$ is observed (weak band) the bending $\mathrm{Si}-\mathrm{O}$ vibration characteristic of ring structures in the glass matrix [51-53]. TO antisymmetric Si-O-Si stretching modes, resulting from the motion of the $\mathrm{O}$ atom back and forth along a line parallel to the $\mathrm{Si}-\mathrm{Si}$ axis [54], are visible at $1050 \mathrm{~cm}^{-1}$ (intense shoulder) and $\sim 1170 \mathrm{~cm}^{-1}$.

Importantly, the shoulder located around $940 \mathrm{~cm}^{-1}$ and the peak at $890 \mathrm{~cm}^{-1}$ are assigned to the $\mathrm{Si}-\mathrm{O}^{-}$non-bridging oxygen $(\mathrm{NBO})^{16-17}$ stretching mode with one $\mathrm{NBO}$ involved per $\mathrm{SiO}_{4}$ tetrahedra $\left(\mathrm{Q}^{3}\right.$ groups, calling for 3 bridging $\mathrm{O}$ and $1 \mathrm{NBO}$ per $\mathrm{SiO}_{4}$ tetrahedra). The presence of NBO can result from calcium ions disrupting the siloxane bridges, as a

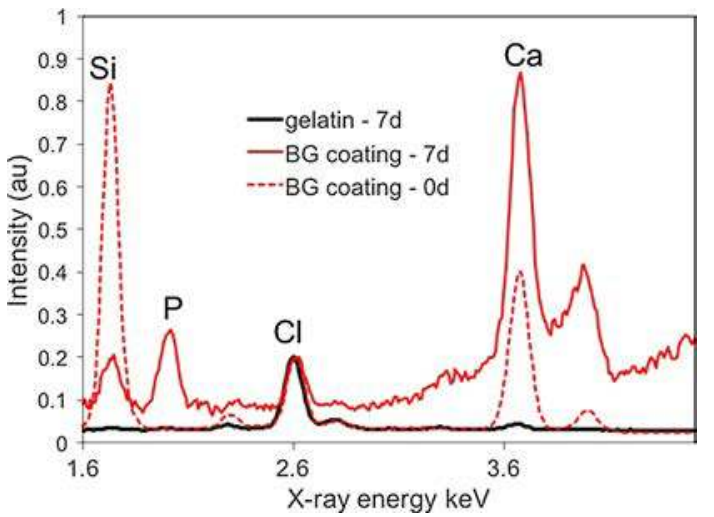

Figure 4 EDXS spectra showing the elemental composition of non-coated gelatin scaffold and BG-coated gelatin scaffold after 7 days of immersion in SBF. The EDXS spectrum of BG-coated gelatin scaffold before immersion is also shown.

result of their successful incorporation into the silicate network. It can also result from the presence of silanols $\mathrm{SiOH}$, which yields $\mathrm{Q}^{3}$ groups as well. In a previous work [48], we had characterized the $\mathrm{SiO}_{2}-$ $\mathrm{CaO}$ BG through ${ }^{29} \mathrm{Si}-{ }^{1} \mathrm{H}$ cross-polarization (CP) MAS (magic-angle spinning) NMR experiments and we demonstrated the incorporation of $\mathrm{Ca}$ into the silicate network, being able to distinguish between the contribution of $\mathrm{Q}_{\mathrm{H}}^{3}$ and $\mathrm{Q}_{\mathrm{Ca}}^{3}$ units. Since the same 
Figure 5 PIXE chemical maps of silicon, calcium and phosphorus inside cross sections of $\mathrm{SiO}_{2}-\mathrm{CaO}$-coated gelatin scaffolds, as a function of increasing interaction time with simulated body fluid. Scale bar is $100 \mu \mathrm{m}$.

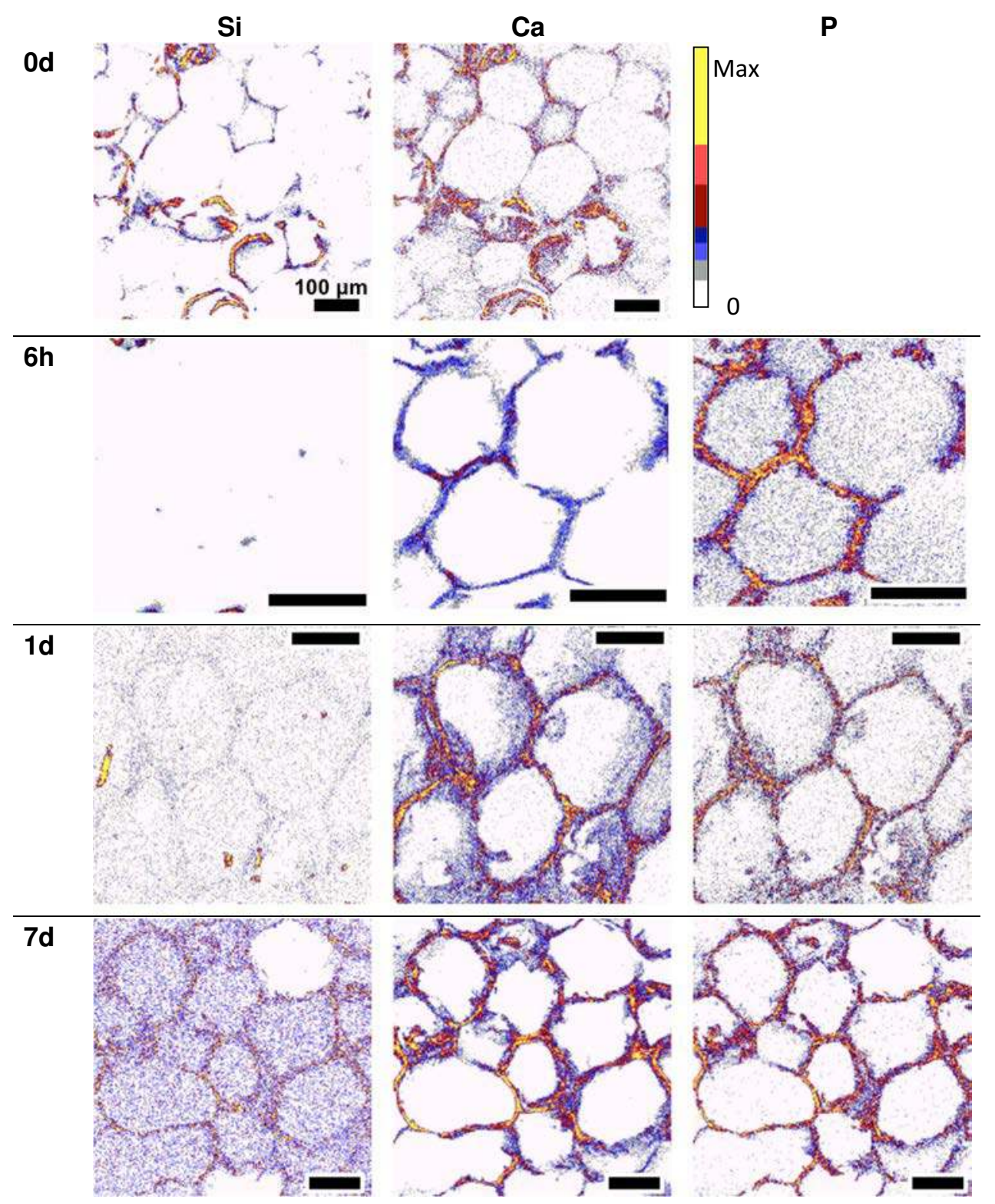

$\mathrm{SiO}_{2}-\mathrm{CaO}$ BG is here considered, and because from Fig. 2 the FTIR fingerprint of silicate networks is identical for the $\mathrm{SiO}_{2}-\mathrm{CaO}$ BG and the $\mathrm{SiO}_{2}-\mathrm{CaO}$ coating, we assume we can interpret the shoulder at $940 \mathrm{~cm}^{-1}$ and the band at $890 \mathrm{~cm}^{-1}$ as an evidence of Ca incorporation.

Moreover, gelatin yielded 3 characteristic bands between 1400 and $1700 \mathrm{~cm}^{-1}$. The $1540 \mathrm{~cm}^{-1}$ peak is associated with amide II absorption arising from N$\mathrm{H}$ bending and $\mathrm{C}-\mathrm{N}$ stretching vibrations [55]. The band at $1440 \mathrm{~cm}^{-1}$ is due to the gelatin amino acids (C-H groups) [56]. The $1650 \mathrm{~cm}^{-1}$ band attribution is more ambiguous since it results both from the $\mathrm{SiOH}$ bonded with molecularly adsorbed water

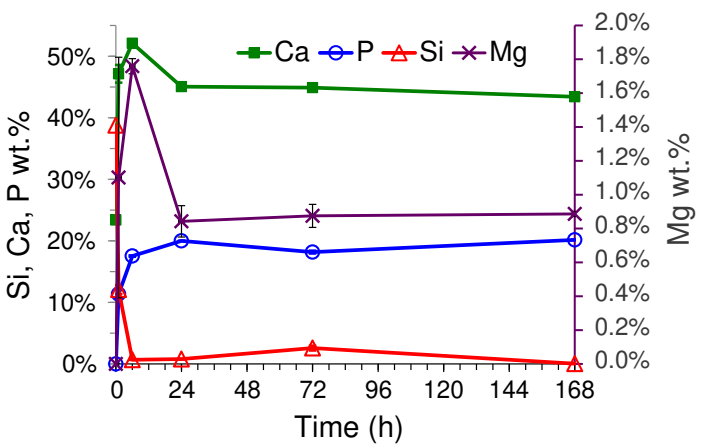

Figure 6 Evolution of $\mathrm{Si}, \mathrm{Ca}, \mathrm{P}, \mathrm{Mg}$ concentrations in the mineralized areas of the scaffolds with increasing time of interaction with SBF. Starting composition of the BG coating is $75 \mathrm{wt} \% \mathrm{SiO}_{2}-25 \mathrm{wt} \% \mathrm{CaO}$. 
$\left(\sim 1630 \mathrm{~cm}^{-1}\right)$ already present on the raw BG spectra [54], and from the $\mathrm{C}=\mathrm{O}$ stretch vibrations $\left(\sim 1650 \mathrm{~cm}^{-1}\right)$ of the peptide linkages of gelatin's amide I [57-59], but its intensity is clearly increased on the BG-coated gelatin spectra compared to raw BG.

The apatite-forming ability of BG-coated gelatin scaffolds was investigated at different scales as visible on Figs. 3, 4, 5 and 6. SEM observations (Fig. 3a) show the macroscopic porous structure is preserved even after 7 days soaking in SBF. Higher magnification (Fig. $3 b$ ) highlights the presence of small precipitates uniformly spread over the scaffold's surface. The ability to induce the homogeneous nucleation of apatite nuclei over the substrate is key for the coating to confer optimum biocompatibility. Images of cross sections of the coating as observed in TEM show it has endured deep structural and morphological changes. As visible on Fig. $3 c$, d, the coating now consists of nanocrystalline needle-like aggregates typical of apatites. Importantly, the coating still presents a uniform thickness all along the gelatin scaffold walls, but its thickness has increased up to $\sim 500 \mathrm{~nm}$ as a result of the apatite crystal growth. Pure crosslinked gelatin scaffolds, i.e. without BG coating, were also immersed in SBF for comparison. SEM observations did not show the formation of any precipitate after 7 days soaking. Figure 4 is an EDXS measurement of the elemental composition of noncoated (pure gelatin) scaffolds compared to BGcoated gelatin scaffolds. Non-coated scaffolds do not show any change in composition, apart from the deposition of chlorides coming from $\mathrm{NaCl}$ salts dissolved in the SBF. On the contrary, BG-coated gelatin scaffolds composition is changed from calcium silicate to calcium phosphate after 7 days soaking in SBF. Therefore, this composition change can be unambiguously attributed to the presence of BG as a bioactive layer coated over the gelatin scaffold.

Figures 5 and 6 investigate in detail the chemical changes endured by the BG-coated gelatin scaffolds during their progressive mineralization as observed through PIXE quantitative chemical imaging. The homogeneity of mineralization throughout the scaffold is well deduced from Fig. 5, demonstrating the efficient circulation of fluids due to the good interconnected structure of the BG-coated scaffolds. The BG coating reacts extremely rapidly; right after $6 \mathrm{~h}$, the $\mathrm{SiO}_{2}-\mathrm{CaO}$ original phase is changed into a calcium phosphate whose composition (see Fig. 5)

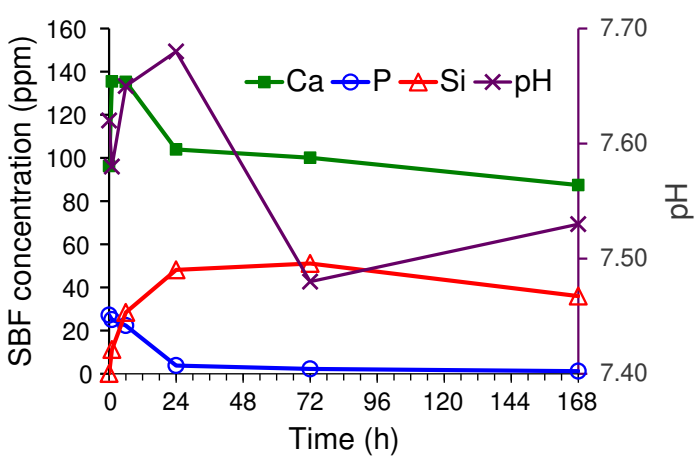

Figure 7 Evolution of SBF composition as determined by ICPAES measurements, with increasing time of inetraction with BGcoated gelatin scaffodls.

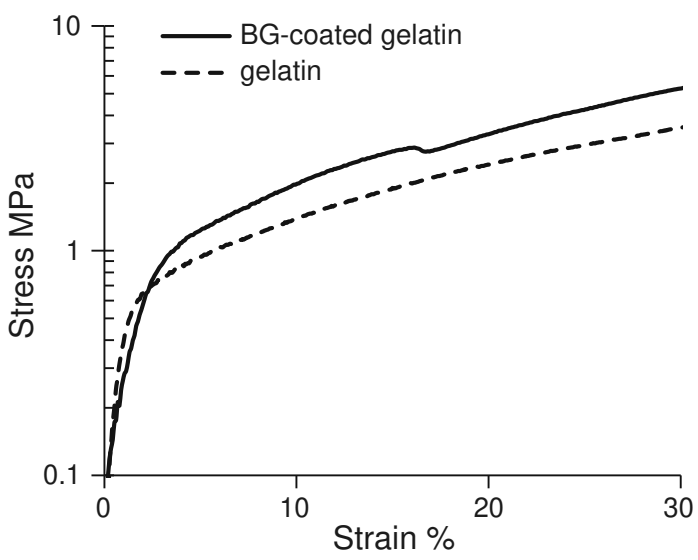

Figure 8 Stress-strain compression curves compared for gelatin scaffolds with $80 \%$ porosity: BG-coated versus non-coated gelatin scaffolds.

stabilizes after $24 \mathrm{~h}$ interaction with SBF. The measured $\mathrm{Ca} / \mathrm{P}$ weight ratio is very close to the 2.2 value (equivalent to 1.67 atomic ratio) of stoichiometric apatite. Interestingly, small amounts $(\sim 1 \mathrm{wt} \%)$ of magnesium are found to be substituted for calcium in the apatite crystals. $\mathrm{As}^{2+}$ is known for stimulation of bone formation and promotion of cellular adhesion and stability due to interaction with integrins [60-62], its incorporation into the coating layer is an attractive feature. From Figs. 6 and 7, which show the evolution of ion concentrations in the coating layer and in the $\mathrm{SBF}$, respectively, we observe the dissolution of the silicate network is very fast, being achieved in the first $24 \mathrm{~h}$ of interaction with SBF. Phosphate ions are depleted from SBF, and all concentrations reach equilibrium right after $24 \mathrm{~h}$ interaction.

Finally, the mechanical properties of BG-coated gelatin scaffolds were tested in compression. Figure 8 
reports the stress-strain curves compared for gelatin scaffolds coated with BG vs non-coated, both having the same $80 \%$ porosity. A slight increase in the yield strength is observed for BG-coated scaffolds. The yield strength is near $1 \mathrm{MPa}$ in both cases, lying in the low range of reported values for trabecular bone $[63,64]$. Because only a thin BG coating layer of $200 \mathrm{~nm}$ has been applied here, the mechanical properties are mainly dependent upon the nature of the polymer chosen to build the scaffold, the toughness being here tightly bound by the gelatin properties.

\section{Conclusion}

Coating a substrate with a bioceramics is a well-known and efficient way of making it become bioactive. However, only very few methods can be applied to polymer scaffolds due to their limited processability post-synthesis. We have employed here a dip-coating process involving a BG sol obtained from an alkoxide route. It was successful to yield a bioactive coating with remarkable homogeneity without the need of thermal treatments, preserving the polymer integrity. We believe it can be applied to any other complex shape or substrate. Gelatin scaffolds are coated with layers of BG with a noticeably uniform $200 \mathrm{~nm}$ thickness. The coating is highly reactive towards SBF and demonstrates a quick apatite-forming ability. Importantly, mineralization takes place homogeneously throughout the scaffold and the coating, while being chemically changed into an apatite phase, keeps its remarkable uniformity and thickness regularity. A slight increase in the mechanical response to compression tests is also observed. These features should enhance the in vivo behaviour of polymer scaffolds and make reconsider the interest of polymers that are non-bioactive for tissue engineering, as both the glass dissolution products from the coating and the newly formed apatite layer help attracting, recruiting and stimulating bone cells. Alternatively, this method can be considered as an efficient way of obtaining a uniform apatite coating on complex polymer shapes at ambient temperature.

\section{Acknowledgements}

The Conseil Régional d'Auvergne is acknowledged for funding ("New Researcher" Grant). The Centre
d'Etudes Nucléaires de Bordeaux-Gradignan and the AIFIRA staff are acknowledged for allowing the PIXE experiments and for technical support.

\section{References}

[1] Ramakrishna S, Mayer J, Wintermantel E, Leong KW (2001) Biomedical applications of polymer-composite materials: a review. Compos Sci Technol 61(9):1189-1224

[2] Surmenev RA, Surmeneva MA, Ivanova AA (2014) Significance of calcium phosphate coatings for the enhancement of new bone osteogenesis: a review. Acta Biomater 10(2):557-579

[3] Heimann RB (2016) The challenge and promise of lowtemperature bioceramic coatings: an editorial. Surf Coat Technol 301:1-5

[4] Creugers N (2002) The survival of hydroxyapatite-coated implants is questioned. Evid Based Dent 3(3):77-78

[5] Coathup MJ, Blackburn J, Goodship AE, Cunningham JL, Smith T, Blunn GW (2005) Role of hydroxyapatite coating in resisting wear particle migration and osteolysis around acetabular components. Biomaterials 26(19):4161-4169

[6] Jones JR (2013) Review of bioactive glass: from Hench to hybrids. Acta Biomater 9(1):4457-4486

[7] Gomez-Vega JM, Saiz E, Tomsia AP, Oku T, Suganuma K, Marshall GW, Marshall SJ (2000) Novel bioactive functionally graded coatings on Ti6Al4V. Adv Mater 12(12):894-898

[8] Fathi MH, Doost A (2008) Mohammadi, preparation and characterization of sol-gel bioactive glass coating for improvement of biocompatibility of human body implant. Mater Sci Eng A 474(1-2):128-133

[9] Garcia C, Ceré S, Durän A (2004) Bioactive coatings prepared by sol-gel on stainless steel 316L. J Non Cryst Solids 348:218-224

[10] Moritz N, Rossi S, Vedel E, Tirri T, Ylänen H, Aro H, Närhi $\mathrm{T}$ (2004) Implants coated with bioactive glass by CO2-laser, an in vivo study. J Mater Sci Mater Med 15(7):795-802

[11] Mistry S, Kundu D, Datta S, Basu D (2011) Comparison of bioactive glass coated and hydroxyapatite coated titanium dental implants in the human jaw bone. Aust Dent J 56(1):68-75

[12] Kokubo T, Kim HM, Miyaji F, Takadama H, Miyazaki T (1999) Ceramic-metal and ceramic-polymer composites prepared by a biomimetic process. Compos A 30(4):405-409

[13] Kokubo T, Kim H-M, Kawashita M (2003) Novel bioactive materials with different mechanical properties. Biomaterials 24(13):2161-2175 
[14] Kokubo T (1996) Formation of biologically active bone-like apatite on metals and polymers by a biomimetic process. Thermochim Acta 280-281:479-490

[15] Tanahashi M, Yao T, Kokubo T, Minoda M, Miyamoto T, Nakamura T, Yamamuro T (1994) Apatite coating on organic polymers by a biomimetic process. J Am Ceram Soc 77(11):2805-2808

[16] Miyaji F, Kim H-M, Handa S, Kokubo T, Nakamura T (1999) Bonelike apatite coating on organic polymers: novel nucleation process using sodium silicate solution. Biomaterials 20(10):913-919

[17] Oliveira AL, Costa SA, Sousa RA, Reis RL (2009) Nucleation and growth of biomimetic apatite layers on $3 \mathrm{D}$ plotted biodegradable polymeric scaffolds: effect of static and dynamic coating conditions. Acta Biomater 5(5):1626-1638

[18] Oliveira AL, Malafaya PB, Reis RL (2003) Sodium silicate gel as a precursor for the in vitro nucleation and growth of a bone-like apatite coating in compact and porous polymeric structures. Biomaterials 24(15):2575-2584

[19] Pernot F, Zarzycki J, Baldet P, Bonnel F, Rabischong P (1985) In vivo corrosion of sodium silicate glasses. J Biomed Mater Res 19(3):293-301

[20] Kent Leach J, Kaigler D, Wang Z, Krebsbach PH, Mooney DJ (2006) Coating of VEGF-releasing scaffolds with bioactive glass for angiogenesis and bone regeneration. Biomaterials 27(17):3249-3255

[21] Day RM, Boccaccini AR, Shurey S, Roether JA, Forbes A, Hench LL, Gabe SM (2004) Assessment of polyglycolic acid mesh and bioactive glass for soft-tissue engineering scaffolds. Biomaterials 25(27):5857-5866

[22] Li H, Chen S, Wu Y, Jiang J, Ge Y, Gao K, Zhang P, Wu L (2012) Enhancement of the osseointegration of a polyethylene terephthalate artificial ligament graft in a bone tunnel using 58S bioglass. Int Orthop 36(1):191-197

[23] Li H, Wu Y, Ge Y, Jiang J, Gao K, Zhang P, Wu L, Chen S (2011) Composite coating of 58S bioglass and hydroxyapatite on a polyethylene terepthalate artificial ligament graft for the graft osseointegration in a bone tunnel. Appl Surf Sci 257(22):9371-9376

[24] Stamboulis A, Hench LL, Boccaccini AR (2002) Mechanical properties of biodegradable polymer sutures coated with bioactive glass. J Mater Sci Mater Med 13(9):843-848

[25] Niiranen H, Törmälä P (1999) Bioabsorbable polymer plates coated with bioactive glass spheres. J Mater Sci Mater Med 10(12):707-710

[26] Lin S, Ionescu C, Pike KJ, Smith ME, Jones JR (2009) Nanostructure evolution and calcium distribution in sol-gel derived bioactive glass. J Mater Chem 19(9):1276-1282

[27] Pereira MM, Clark AE, Hench LL (1994) Calcium phosphate formation on sol-gel-derived bioactive glasses in vitro. J Biomed Mater Res 28(6):693-698
[28] Ramila A, Balas F, Vallet-Regi M (2002) Synthesis routes for bioactive Sol-Gel glasses: alkoxides versus nitrates. Chem Mater 14(2):542-548

[29] Yu B, Turdean-Ionescu CA, Martin RA, Newport RJ, Hanna JV, Smith ME, Jones JR (2012) Effect of calcium source on structure and properties of sol-gel derived bioactive glasses. Langmuir 28(50):17465-17476

[30] Balian G, Bowes JH (1977) The structure and properties of collagen. Academic Press, London

[31] Cortesi R, Nastruzzi C, Davis SS (1998) Sugar cross-linked gelatin for controlled release: microspheres and disks. Biomaterials 19(18):1641-1649

[32] Okino H, Manabe T, Tanaka M, Matsuda T (2003) Novel therapeutic strategy for prevention of malignant tumor recurrence after surgery: local delivery and prolonged release of adenovirus immobilized in photocured, tissue-adhesive gelatinous matrix. J Biomed Mater Res Part A 66A(3):643-651

[33] Tao X, Shaolin L, Yaoting Y (2003) Preparation and culture of hepatocyte on gelatin microcarriers. J Biomed Mater Res Part A 65A(2):306-310

[34] Elisabettacenni, Ciapetti G, Stea S, Corradini A, Carozzi F (2000) Biocompatibility and performance in vitro of a hemostatic gelatin sponge. J Biomater Sci Polym Ed 11(7):685-699

[35] Chen K-Y, Shyu P-C, Dong G-C, Chen Y-S, Kuo W-W, Yao C-H (2009) Reconstruction of calvarial defect using a tricalcium phosphate-oligomeric proanthocyanidins crosslinked gelatin composite. Biomaterials 30(9):1682-1688

[36] Chen T-M, Yao C-H, Wang H-J, Chou G-H, Lee T-W, Lin F-H (1998) Evaluation of a novel malleable, biodegradable osteoconductive composite in a rabbit cranial defect model. Mater Chem Phys 55(1):44-50

[37] Yao C-H, Liu B-S, Hsu S-H, Chen Y-S (2005) Calvarial bone response to a tricalcium phosphate-genipin crosslinked gelatin composite. Biomaterials 26(16):3065-3074

[38] Handa T, Anada T, Honda Y, Yamazaki H, Kobayashi K, Kanda N, Kamakura S, Echigo S, Suzuki O (2012) The effect of an octacalcium phosphate co-precipitated gelatin composite on the repair of critical-sized rat calvarial defects. Acta Biomater 8(3):1190-1200

[39] Lien S-M, Chien C-H, Huang T-J (2009) A novel osteochondral scaffold of ceramic-gelatin assembly for articular cartilage repair. Mater Sci Eng C 29(1):315-321

[40] Descamps M, Duhoo T, Monchau F, Lu J, Hardouin P, Hornez JC, Leriche A (2008) Manufacture of macroporous beta-tricalcium phosphate bioceramics. J Eur Ceram Soc 28(1):149-157

[41] Draghi L, Resta S, Pirozzolo M, Tanzi M (2005) Microspheres leaching for scaffold porosity control. J Mater Sci Mater Med 1612:1093-1097 
[42] Descamps M, Richart O, Hardouin P, Hornez JC, Leriche A (2008) Synthesis of macroporous beta-tricalcium phosphate with controlled porous architectural. Ceram Int 34(5):1131-1137

[43] Callcut S, Knowles JC (2002) Correlation between structure and compressive strength in a reticulated glass-reinforced hydroxyapatite foam. J Mater Sci Mater Med 13(5):485-489

[44] Kokubo T, Takadama H (2006) How useful is SBF in predicting in vivo bone bioactivity? Biomaterials 27(15):29072915

[45] Bohner M, Lemaitre J (2009) Can bioactivity be tested in vitro with SBF solution? Biomaterials 30(12):2175-2179

[46] Skipper LJ, Sowrey FE, Pickup DM, Drake KO, Smith ME, Saravanapavan P, Hench LL, Newport RJ (2005) The structure of a bioactive calcia-silica sol-gel glass. J Mater Chem 15(24):2369-2374

[47] Poologasundarampillai G, Yu B, Jones JR, Kasuga T (2011) Electrospun silica/PLLA hybrid materials for skeletal regeneration. Soft Matter 7(21):10241

[48] Dieudonné X, Montouillout V, Jallot E, Fayon F, Lao J (2014) Bioactive glass hybrids: a simple route towards the gelatin- $\mathrm{SiO} 2-\mathrm{CaO}$ system. Chem Commun 50(63):87018704

[49] Brinker CJ (1988) Hydrolysis and condensation of silicates: effects on structure. J Non Cryst Solids 100(1):31-50

[50] Serra J, Gonzàlez P, Liste S, Serra C, Chiussi S, Leon B, Pérez-Amor M, Ylänen HO, Hupa M (2003) FTIR and XPS studies of bioactive silica based glasses. J Non Cryst Solids 332(1):20-27

[51] Aguiar H, Serra J, Gonzàlez P, Leon B (2009) Structural study of sol-gel silicate glasses by IR and Raman spectroscopies. J Non Cryst Solids 355(8):475-480

[52] Brinker CJ, Scherer GW (1990) Sol-gel science: the physics and chemistry of sol-gel processing. Academic press, New York

[53] Sitarz M, Handke M, Mozgawa W (1999) Calculations of silicooxygen ring vibration frequencies, spectrochim. Acta Part A Mol Biomol Spectrosc 55(14):2831-2837

[54] Innocenzi P (2003) Infrared spectroscopy of sol-gel derived silica-based films: a spectra-microstructure overview. J Non Cryst Solids 316(2-3):309-319
[55] Cebi N, Durak MZ, Toker OS, Sagdic O, Arici M (2016) An evaluation of Fourier transforms infrared spectroscopy method for the classification and discrimination of bovine, porcine and fish gelatins. Food Chem 190:1109-1115

[56] Kim H-W, Knowles JC, Kim H-E (2005) Porous scaffolds of gelatin-hydroxyapatite nanocomposites obtained by biomimetic approach: characterization and antibiotic drug release. J Biomed Mater Res 74B(2):686-698

[57] Bandekar J (1992) Amide modes and protein conformation. Biochim et Biophys Acta (BBA) Protein Struct Mol Enzymol 1120(2):123-143

[58] Jackson M, Mantsch HH (1995) The use and misuse of FTIR spectroscopy in the determination of protein structure. Crit Rev Biochem Mol Biol 30(2):95-120

[59] Birshtein VY, Tul'chinskii VM (1982) A study of gelatin by IR spectroscopy. Chem Nat Compd 18(6):697-700

[60] Hoppe A, Güldal NS, Boccaccini AR (2011) A review of the biological response to ionic dissolution products from bioactive glasses and glass-ceramics. Biomaterials 32(11):2757-2774

[61] Zreiqat H, Howlett CR, Zannettino A, Evans P, SchulzeTanzil G, Knabe C, Shakibaei M (2002) Mechanisms of magnesium-stimulated adhesion of osteoblastic cells to commonly used orthopaedic implants. J Biomed Mater Res 62(2):175-184

[62] Yamasaki Y, Yoshida Y, Okazaki M, Shimazu A, Uchida T, Kubo T, Akagawa Y, Hamada Y, Takahashi J, Matsuura N (2002) Synthesis of functionally graded $\mathrm{MgCO} 3$ apatite accelerating osteoblast adhesion. J Biomed Mater Res 62(1):99-105

[63] Keaveny TM, Morgan EF, Yeh OC (2003) Bone biomechanics. In: Kutz M (ed) Standard handbook of biomedical engineering and design. McGraw-Hill Professional, New York, pp 221-243

[64] Kopperdahl DL, Keaveny TM (1998) Yield strain behavior of trabecular bone. J Biomech 31(7):601-608 